\title{
Variability of relaxed expiratory volume and forced inspiratory volume
}

\author{
M.K. TA N D N and A. H. CA M P B E L L \\ Repatriation Department, Central Office, 312 St. Kilda Road, South Melbourne, Victoria, Australia
}

Measurements of relaxed expiratory volume in one second $\left(\operatorname{REV}_{1 \cdot 0}\right)$ and forced inspiratory volume in one second $\left(\mathrm{FIV}_{1 \cdot 0}\right)$ were made on 50 subjects on two occasions to know the variability of these procedures in the individual subject. The mean coefficients of variation for REV $_{1 \cdot 0}$ and FIV $_{1 \cdot 0}$ were $6.74 \%$ and $8.92 \%$, respectively. The $95 \%$ confidence limit of difference between highest readings obtained on two occasions for REV $_{1.0}$ and $F I V_{1.0}$ was 0.38 litre and 0.214 litre, respectively. These results compare favourably with similar data reported for other ventilatory tests. We feel that if a little time is spent teaching subjects to produce REVs, then reproducible results may be obtained.

Tracheobronchial collapse during forced expiratory manœuvres has been shown to occur in some cases of obstructive airway disorders (Dayman, 1951; Gandevia, 1963 ; Campbell and Faulks, 1965). In addition to other conventional procedures, it has been suggested that in such cases tests of sub-maximal expiratory effort, i.e., onesecond relaxed expiratory volume $\left(\mathrm{REV}_{1 \cdot 0}\right)$ (Gandevia, 1963; Tandon and Campbell, 1968), and tests involving forced inspiration, i.e., onesecond forced inspiratory volume $\left(\mathrm{FIV}_{1 \cdot 0}\right)$ (Tandon and Campbell, 1968) and peak inspiratory flow rate (Saunders, 1967), should be used.

However, $\mathrm{REV}_{1 \cdot 0}$ is difficult to perform properly and FIV $_{1 \cdot 0}$ is effort dependent. Hence these tests may not be so reproducible as tests of forced expiration, which are to some extent independent of the effort applied (Fry and Hyatt, 1960). Therefore, before these two tests can be recommended for general use, their variability should be known. An attempt has been made to determine the variability of $\mathrm{REV}_{1 \cdot 0}$ and $\mathrm{FIV}_{1 \cdot 0}$ in the individual subject.

\section{SUBJECTS AND METHODS}

Fifty subjects from the staff of R.G.H., Heidelberg, Victoria, and the persons attending the Chest Clinic for their annual review of pulmonary tuberculosis, chronic bronchitis, and emphysema were taken in a random fashion to give a wide variety of cases varying from those with no airways obstruction to those with severe airways obstruction. All were men aged $40-60$ years.
A water-filled spirometer, with a fast recording drum, was used to measure the $\mathrm{REV}_{1.0}$ and $\mathrm{FIV}_{1.0}$.

PROCEDURE For performing REV $_{1.0}$ the subjects werea asked to take in as deep a breath as possible, holdळ the breath, put the mask on the face and, when instructed, breathe all the air out with a deep sigh, $\overline{\bar{O}}$ letting the chest and abdomen collapse without any effort to force out the air. For FIV ${ }_{1.0}$ the instructions? given were first to breathe out all the air and, when no more could be exhaled, to hold the breath, put the mask on the face and, when told, to inhale aso fast and as deep as possible. All the subjects practised both the manœuvres till they were familiar withothem. Three readings of each REV $_{1.0}$ and FIV $_{1.0}$ were first recorded and the subjects were asked to rest for half an hour before recording a second set of three readings for both the procedures. Between the recording of the two sets of readings the subjects were? requested to refrain from smoking. The same person performed all the tests on all the subjects.

The time taken for indoctrination of patientsu befor $\epsilon$ getting a satisfactory reproducible recording of REV varied from 2 to 5 minutes. Only two sub N jects could not master the technique and these have been excluded. We did not have much difficulty witho this procedure, because the person doing these tests had over 10 years' experience with these procedures.

\section{RESULTS}

The coefficient of variation for the six readingso for $\operatorname{REV}_{1 \cdot 0}$ and FIV $_{1.0}$ was calculated for all the cases, and then the mean for the 50 cases was calculated. The mean coefficient of variation for $\mathrm{REV}_{1 \cdot 0}$ was $6.74 \%$ and for $\mathrm{FIV}_{1 \cdot 0} 8.92 \%$. 
On comparing the results obtained on the first occasion with those obtained 30 minutes later, the mean difference between the highest readings obtained on two occasions was $0.026 \pm 0.099$ litre for FIV $_{1.0}$ and for $\mathrm{REV}_{1.0}$ it was $0.034 \pm 0.173$ litre. These differences were not significant (Table I). The $95 \%$ confidence limits of difference for FIV $_{1 \cdot 0}$ and $\mathrm{REV}_{1.0}$, respectively, were 0.214 and 0.38 litre.

Table II gives the distribution of cases showing improvement, deterioration and no change in

\section{T A B L E I}

MEAN DIFFERENCE BETWEEN HIGHEST VALUES ON TWO OCCASIONS

\begin{tabular}{l|c|c|c|c}
\hline & $\begin{array}{c}\text { Mean } \\
\text { Difference }\end{array}$ & $\begin{array}{c}\text { Standard } \\
\text { Deviation }\end{array}$ & $\begin{array}{c}95 \% \\
\text { Confidence } \\
\text { Limit of } \\
\text { Difference }\end{array}$ & $P$ \\
\hline FIV $_{1.0}(1)$. & $\begin{array}{l}0.026 \\
\text { REV }_{1.0}(1 .)\end{array}$ & $\begin{array}{l} \pm 0.099 \\
\pm 0.173\end{array}$ & $\begin{array}{l}\mathbf{0 . 2 1 4} \\
\mathbf{0 . 3 8 0}\end{array}$ & $\begin{array}{c}\text { N.S. } \\
\text { N.S. }\end{array}$ \\
\hline
\end{tabular}

\section{T A B L E I I}

DISTRIBUTION OF CASES FOR RESULTS OF SECOND ATTEMPT

\begin{tabular}{l|c|c|c}
\hline & Improvement & Deterioration & No Change \\
REV $_{1.0}$ & 21 & 20 & 9 \\
FIV $_{1.0}$ & 16 & 23 & 11 \\
\hline
\end{tabular}

their highest readings in the second attempt compared with the highest readings for the first attempts for both tests. While performing $\operatorname{REV}_{1 \cdot 0}$ there were almost as many who showed improvement as those showing deterioration. Relatively more cases had lower readings for FIV $_{1 \cdot 0}$ in the second attempt than those showing improvement in the second attempt.

\section{DISCUSSION}

The coefficients of variation for $\mathrm{REV}_{1 \cdot 0}$ and $\mathrm{FIV}_{1 \cdot 0}$ compare favourably with the values reported for FEV $_{1 \cdot 0}$ and peak expiratory flow rate (PEF) (Table III).

\section{T A B L E I I I}

COEFFICIENTS OF VARIATION FOR FEV F $_{10}$ AND PEF REPORTED EARLIER AND FOR REV 1.0 AND FIV 1.0 OBREPORTED EARLIER AND FOR REV 1 .0 AN
TAINED IN THE PRESENT STUDY

\begin{tabular}{|c|c|c|c|}
\hline & $\begin{array}{l}\text { Lockhart } \\
\text { Smith, Mair, } \\
\text { and Wilson } \\
(1960)\end{array}$ & $\begin{array}{c}\text { Fairbairn } \\
\text { Fletcher, Tinker, } \\
\text { and Wood } \\
\text { (1962) }\end{array}$ & $\begin{array}{l}\text { Present } \\
\text { Study }\end{array}$ \\
\hline $\begin{array}{l}\text { FEV }_{1.0} \\
\text { PEF } \\
\text { REV }_{1.0} \\
\text { FIV }_{1.0}\end{array}$ & $\begin{array}{c}11 \cdot 5 \\
6 \cdot 0 \\
-\end{array}$ & $\begin{array}{c}4 \cdot 3 \\
5 \cdot 4 \text { to } 6 \cdot 0 \\
=\end{array}$ & $\begin{array}{l}\overline{\overline{7}} \\
6.74 \\
8.92\end{array}$ \\
\hline
\end{tabular}

The values for the $95 \%$ confidence limit of the difference for $\mathrm{REV}_{1 \cdot 0}$ and $\mathrm{FIV}_{1 \cdot 0}$ are also comparable (Table IV) to those reported for vital capacity (VC) and $\mathrm{FEV}_{1 \cdot 0}$ (Davidson, 1966).

\section{T A B L E I V}

$95 \%$ CONFIDENCE LIMITS FOR FEV 1.0 AND VITAL CAPACITY REPORTED EARLIER AND FOR REV ${ }_{1.0}$ AND FIV $_{1,0}$ IN THE PRESENT STUDY

\begin{tabular}{l|c|c}
\hline & Present Study & Davidson (1966) \\
\hline No. of paired & 50 & 56 \\
comparisons & $\overline{-}$ & $0 \cdot 25$ \\
VEV $_{1}$ (litres) & (litres) & $0 \cdot 26$ \\
REV $_{1.0}$ (litres) & $0 \cdot 38$ & - \\
FIV & $0 \cdot 214$ & (litres) \\
\hline
\end{tabular}

Saunders (1967) observed that the 'within patient' variance for peak inspiratory flow rate was not excessive and was not always greater for peak inspiratory flow rate than for peak expiratory flow rate.

Despite the slightly greater complexity in the proper performance of $\mathrm{REV}_{1 \cdot 0}$ and the effortdependence of $\mathrm{FIV}_{1 \cdot 0}$, in experienced hands the variabilities for both these procedures compare favourably with those reported for other ventilatory tests. It seems, therefore, that these tests can be recommended for assessing the ventilatory capacity of cases with chronic bronchitis and emphysema.

We wish to thank the Chairman of the Repatriation Commission for permission to publish this paper, and Sister E. R. Doherty for performing these tests.

\section{REFERENCES}

Campbell, A. H., and Faulks, L. W. (1965). Expiratory air-flow pattern in tracheobronchial collapse. Amer. Rev. resp. Dis., 92, 781.

Davidson, L. (1966). Repeatability of respiratory data in the individual subject. Thorax, 21, 47.

Dayman, H. (1951). Mechanics of airflow in health and in emphysema. J. clin. Invest., 30, 1175.

Fairbairn, A. S., Fletcher, C. M., Tinker, C. M., and Wood, C. H. (1962). A comparison of spirometric and peak expiratory flow measurements in men with and without chronic bronchitis. Thorax, 17, 168 .

Gandevia, B. (1963). The spirogram of gross expiratory tracheobronchial collapse in emphysema. Quart. J. Med., 32, 23.

Lockhart, W., Smith, D. H., Mair, A., and Wilson, W. A. (1960) Practical experience with the peak flow meter. Brit. med. J., $1,37$.

Macklem, P. T., Fraser, R. G., and Brown, W. G. (1965). Bronchial pressure measurements in emphysema and bronchitis. $J$. clin. Invest., 44, 897.

Saunders, K. B. (1967). Bronchodilator response patterns in patients with chronic airways obstruction: use of peak inspiratory flow rate. Brit. med. J., 2, 399.

Tandon, M. K., and Campbell, A. H. (1968). Assessment of bronchodilator response in chronic bronchitis and emphysema: use of relaxed expiratory volume and forced inspiratory volume. Aust. Ann. Med., 17, 192. 